\title{
A Markov Switching Analysis of Contagion in THE EMS
}

\author{
Alex Mandilaras* \\ Graham Bird $^{\dagger}$ \\ University of Surrey \\ University of Surrey
}

February 2010

\begin{abstract}
This paper applies the multivariate version of the Forbes and Rigobon (2002) contagion test, as proposed by Dungey et al. (2004), to detect contagion effects in the Exchange Rate Mechanism (ERM) of the European Monetary System (EMS). Crisis and non-crisis observations are determined endogenously via a Markov-switching vector autoregression (MS-VAR). We show that the MS-VAR is suitable for this purpose, as it does particularly well in identifying the 11 realignments of the ERM. We examine whether Denmark's rejection of the Maastricht Treaty and Italy's competitiveness problems affected other EMS participants and find evidence for contagion.
\end{abstract}

JEL Classification: F31, F33

Keywords: Currency crisis, contagion, Markov switching

\footnotetext{
*Corresponding author. Department of Economics, University of Surrey, Guildford, GU2 7XH. E-mail address: a.mandilaras@surrey.ac.uk. Tel.: +44 (0)1483 682768. Fax: +44 (0) 1483689548.

${ }^{\dagger}$ Department of Economics, University of Surrey, Guildford, GU2 7XH. E-mail address: g.bird@surrey.ac.uk. Tel.: +44 (0)1483 689325. Fax: +44 (0) 1483689548.
} 


\section{Introduction}

Despite the apparent stability of the international monetary system since the early 1990s, often attributed to the adoption of more flexible exchange rate regimes and inflation targeting (see, e.g. Rose, 2007), few would argue that currency crises are a thing of the past. In fact, for the period 1973-97 Bordo et al. (2001) find that the frequency of currency crises was higher than in the preceding post-war period. More recently, the crises of Argentina in 2001 and Brazil in 2002 served as useful, but costly, reminders of the dire consequences of failing to recognize the dangers of capital flight. As policymakers have tried to steer clear of such effects there has, indeed, been a move towards more flexible exchange rate systems. But this trend is not universal: excluding 41 countries that do not have a separate legal tender, 75 countries still operate some form of peg compared to 76 running an independent or managed float. ${ }^{1}$

The theoretical literature has grown and evolved to offer various explanations for the apparently ever-changing crisis phenomena. The initial approach of unsustainable monetary fundamentals (see Krugman, 1979) was followed by game-theoretic models with multiple equilibria (see Obstfeld, 1986). The latter predict that circumstances can arise in which investors' perception of a government's objectives can lead to a crisis even when the fundamentals are in order. More recently, and as a result of the inability of existing models to predict the Asian crisis, so called third generation models evolved. These explain crises in terms of moral hazard and contagion effects and highlight the role of banking supervision (see, e.g. Corsetti et al., 1999).

In this paper, we propose a Markov regime-switching methodology to model movements in the foreign exchange (FX) markets and their transmission across countries. Such models have been extensively used in the business cycle literature (see, e.g. Hamilton, 1989 and Krolzig, 2001, among others) and, more recently, in

\footnotetext{
${ }^{1}$ See the IMF's de facto classification of exchange rate regimes and monetary policy framework at http://www.imf.org/external/np/mfd/er/2006/eng/0706.htm (as of July 31st, 2006).
} 
currency crisis research. A crisis can be thought of as a switch from a state of the world with zero or negative FX market pressure (a 'tranquil' regime) to one where the pressure is positive and higher (a 'crisis' regime). In other words, there are jumps in the mean and -depending on the setting-changes in the volatility of the time series across different regimes. We apply this methodology to the European Monetary System (EMS). In our setting three phases of the EMS are captured accurately: the 'old' EMS when several realignments took place, the 'new' EMS when there were no adjustments of the exchange rate bands and the final stage characterized by extreme FX pressure that culminated in the abandonment of the mechanism.

Our approach is simple and intuitive and does not require the a priori breakdown of the sample into crisis and non-crisis periods. Crisis periods are endogenously determined. Adopting this methodology has the advantage that it enables us to calculate the probabilities of a shift between the two regimes, as well as their duration. Hence, we obtain a measure of how crisis-prone the EMS was.

Moreover, the use of a FX pressure index enables us to focus on spillovers in the FX market. The MS-VAR allows us to answer the question of whether correlations between countries vary across regimes. We focus further on the question of contagion by using the Dungey et al. (2004) multivariate version of the Forbes and Rigobon (2002) formula to test explicitly for changes in market linkages. We find evidence that volatility transmission is 'over and above' what would be explained by the transmission mechanism that prevails during tranquil periods. Subject to some caveats, which we discuss in a later section, this constitutes evidence of 'contagion' effects.

\section{Contagion in the Literature}

The exchange rate mechanism of the European monetary system came to life in March 1979 in order to reduce the exchange rate volatility between the (then) European Economic Community members' currencies. Its main feature was that fluctuations in bilateral exchange rates, expressed in ECU (the European Currency Unit 
-a precursor of the Euro), should be contained within a \pm 2.25 percent band around a central parity. ${ }^{2}$ A series of realignments (18 in total $)^{3}$ and general instability eventually led to the widening of the band to \pm 15 percent in August 2003. ${ }^{4}$

In this paper we explore potential contagion effects within the ERM mechanism. But what constitutes contagion? A loose interpretation of the term would include the simple transmission of shocks from one country to another through existing economic channels (e.g. the current account). This is the point of view taken in Eichengreen et al. (1996). Using a panel of quarterly data (1959-93) for 20 developed economies they find that the probability of a crisis increases significantly as a result of a crisis occurring somewhere else. The channels put forward as potential transmitters of shocks are trade links and comparable macroeconomic policies and conditions. Both are found to be significant factors in the propagation of shocks across countries, with the trade effect being stronger. The caveat issued by the authors is that common shocks may be another driving influence for the results even though, clearly, it is not the only one.

Further evidence on the trade link is provided by Glick and Rose (1999). Using cross-sectional data for five different crisis incidents (the Bretton Woods demise in 1971, the collapse of the Smithsonian Agreement in 1973, the EMS crisis in 1992-93, the Mexican crisis in 1994-95 and the Asian crisis in 1997-98) they find that the trade channel is important either through direct trade between countries or through trade competition for the same markets. Specifically, their direct trade variable is defined as

$$
\operatorname{DirectTrade}_{i}=1-\frac{\left|x_{i 0}-x_{0 i}\right|}{x_{i 0}+x_{0 i}}
$$

with exports $x$ and countries $i$ and 0 , whereas the trade linkage variable is measured

\footnotetext{
${ }^{2}$ The exception was Italy, whose currency had a wider band of \pm 6 percent.

${ }^{3}$ The precise dates of these realignments are: 24 September 1979, 30 November 1979, 23 March 1981, 5 October 1981, 22 February 1982, 14 June 1982, 21 March 1983, 18 May 1983, 22 July 1985, 7 April 1986, 4 August 1986, 12 January 1987, 8 January 1990, 14 September 1992, 17 September 1992, 23 November 1992, 1 January 1993 and 14 May 1993. On 3 August 1993 the exchange rate bands widened. Source: Eurostat.

${ }^{4}$ With the exception of Germany and the Netherlands that maintained the narrower bands for the Mark and the Guilder, respectively.
} 
as

$$
\operatorname{Trade}_{i}=\sum\left[\frac{x_{0 k}+x_{k 0}}{x_{0}+x_{i}} \times\left(1-\frac{x_{i k}-x_{0 k}}{x_{i k}+x_{0 k}}\right)\right],
$$

with $x_{i k}$ denoting bilateral exports from country $i$ to $k$ and $x_{i}$ being overall exports of country $i$. Country 0 is the first victim (or "ground zero", as the authors call it) of a crisis: Germany for the first two crises examined and Finland, Mexico and Thailand for the remaining three, respectively. The key finding is that an increase in any of the trade variables corresponds to a significant increase in the probability of a crisis in the EMS.

A stricter definition of contagion would not encompass a propagation of shocks through real channels that remain unchanged during different states of the world. Forbes and Rigobon (2002) concentrate on the change in cross-market linkages following a country-specific shock. In other words, if any real linkages existed prior to the shock and remained unaltered during and after it, then any increased correlation between asset prices (e.g. stock prices) is not evidence of contagion from one market to the other, just interdependence. If, however, there is a significant change in these linkages, the term contagion (or shift contagion) can be used. This distinction is justified as during calm periods exchange rates are normally driven by fundamentals, whereas during crisis periods investor confidence/psychology takes over. Focusing on European money markets Favero and Giavazzi (2002) confirm that non-linearities were present ("a general phenomenon") in the propagation of shocks in the EMS.

The Markov-switching framework is ideal to examine the change in correlations across different states of the world, in this case crisis and non-crisis ones. The idea of having discrete random changes in regime modeled as a Markov chain is straightforward. An $N$-state Markov chain can be described by $P\left\{r_{t}=k \mid r_{t-1}=\right.$ $\left.j, r_{t-2}=i, \ldots\right\}=P\left\{r_{t}=k \mid r_{t-1}=j\right\}=p_{j k}$, where $r_{t}$ is a random variable taking values $1,2, \ldots, N$. This process implies that $r_{t}$ depends only on the most recent value $r_{t-1}$; in other words, previous states do not affect the current state. ${ }^{5}$ There

\footnotetext{
${ }^{5}$ See Krolzig (1997), chapters 1 and 2 and Hamilton (1994), chapter 22, for a detailed statistical
} 
are several examples of studies of currency or financial crises in a Markov-switching autoregressive framework; see, e.g. Amato and Tronzano (2000), Martinez-Peria (2002), Cerra and Saxena (2002) and Abiad (2003). In contrast, there are very few examples that have used this framework to study contagion explicitly. ${ }^{6}$ Two such examples are Billio et al. (2005) and Gravelle et al. (2006).

In the first of these papers, Billio et al. (2005) examine the Asian crisis. The main arguments put forward for the use of regime switching are similar to those we employ; namely: (i) the endogenous selection of crisis and non-crisis periods alleviates the need for a priori categorization of observations into any of these two categories, and (ii) the correlations are conditioned on each regime and, hence, facilitate the analysis of market linkages. The main finding is that there is evidence of interdependence but not contagion from Hong Kong to the European and U.S. stock markets in 1997. In the second paper, Gravelle et al. (2006) concentrate on Latin America. Their findings suggest that shocks are transmitted through long-run real links even though there is some evidence that short-term effects are present in periods of high turbulence.

Here, we advance this agenda exploring contagion in the ERM by applying the multivariate version of Forbes and Rigobon (2002), described in Dungey et al. (2004).

\section{More on the MSVAR}

The behavior of market correlations across crisis and non-crisis regimes is of interest to policymakers who may use the past as a guide to what to expect during periods of turmoil. It is also of interest to FX investors. For example, currencies whose returns are uncorrelated during good times but tend to synchronize during bad times will not offer the expected diversification benefits when these would be needed the most.

review of Markov chains and their use in regime switching models.

${ }^{6}$ Of course, there is a sizeable applied literature of contagion tests using alternative methodologies; see, e.g. Billio and Pelizzon (2003), Baur and Fry (2006) and Fazio (2007). 
From this paper's point of view, we aim to build a parsimonious specification that describes the ERM experience accurately and identifies correctly most realignments as crisis periods. We achieve this by opting for a two-regime setting without fundamentals for our analysis. The realistic behavior of the model allows us to use the resulting classification of observations across the two regimes to conduct the Dungy et al. (2004) multivariate version of the Forbes and Rigobon (2002) test -henceforth FRM.

The choice of the number of regimes entails a degree of subjectivity, as the literature raises several caveats against applying particular statistical criteria. ${ }^{7}$ Our choice of two regimes is consistent with the criterion of parsimony given that the available degrees of freedom decline fast when adding parameters for estimation to a vector autoregressive framework. Moreover, modeling the process with two-regimes is intuitive for an ERM application given that the data show the prevalence of either a tranquil state with relative stability (or moderate tendencies for exchange rate appreciation) or a turbulent crisis state with strong depreciating pressures. Our estimates are consistent with this observation. On the downside, an implication of this assumption is that there are no permanent shifts of regime, as the model always reverts to the non-crisis state.

The decision to undertake the analysis within a static framework without fundamentals is also important. Implicitly, the assumption is that the probability of switching from one state to another is not affected by exogenous variables. This does not pose a problem for the purpose of this paper, which is to analyze state-dependent correlations and to explore whether shifts can be attributed to contagion. So called time-varying transition probability (TVTP) models allow for fundamentals at the cost of greater complication. ${ }^{8}$ The choice of exogenous variables in such a setting is

\footnotetext{
${ }^{7}$ For example, Psaradakis et al. (2003) find evidence that the Akaike Information Criterion is a reasonable guide to regime number selection but they confirm this only for autoregressive processes where the autoregressive parameter is known, and the change in parameters and sample are not too small. Overall, they argue that the so called three pattern method is probably the best, under these assumptions.

${ }^{8}$ See Filardo (1994) for details of the Bayesian estimation.
} 
crucial and would go beyond our modest goals. It is also a possibility that market sentiment may drive changes in correlations, especially during turmoil in the FX market. For example King et al. (1995) argue that "changes in correlations across markets are driven primarily by unobservable variables".

\section{The Data}

The FX pressure measure we use is a market pressure indicator (MPI) in the spirit of Eichengreen et al. (1996). The index consists of time series on the nominal exchange rate change against the Deutsche Mark $(X R)$, the change in the interest rate differential with Germany $(I R D)$, and the change in foreign exchange reserves $(R E S)$-in US Dollars. ${ }^{9}$ A market pressure index is a superior measure to one based on simple nominal exchange rates, as it captures all pressure in the foreign exchange market, including unsuccessful speculative attacks. For example, the monetary authorities might be able to fend off an attack by raising their policy rate or by buying domestic currency (and thus spending their international reserves). This activity would not register in the exchange rate series, but it is evident in the MPI, which is, formally, expressed as:

$$
M P I=\alpha X R+\beta I R D-\gamma R E S
$$

For the $X R$ and $R E S$ series percentage changes were created by taking the first difference of the natural logarithms. For IRD we take the first difference since the series is already expressed in percentage points. An increase in the value of the index signifies pressures in the FX market, since a higher nominal exchange rate implies a depreciation of the domestic currency and higher interest differentials and reduced reserves show the implementation of defending policies by the central bank. The minus sign in the equation above ensures that a reduction in reserves translates

\footnotetext{
${ }^{9}$ Eichengreen et al. (1996) express reserves as the difference between a country's percent change of reserve holdings and Germany's percent change of reserve holdings. Quantitatively, inclusion of German reserves does not make a difference to the results, which we report later. German reserves were the least volatile during the sample period.
} 
into an increase in the value of the index. The weights $\alpha, \beta$ and $\gamma$ are determined by applying the following formula:

$$
w_{i}=\left(\frac{1}{S t D e v_{i}}\right) /\left(\frac{1}{S t D e v_{X R}}+\frac{1}{S t D e v_{I R D}}+\frac{1}{S t D e v_{R E S}}\right)
$$

where $w_{i}=\alpha, \beta, \gamma$, and $i=X R, I R D, R E S$. StDev stands for the standard deviation. $^{10}$

\section{[Insert Table 1 about here]}

The countries in our sample are Belgium, Denmark, France, Ireland, Italy and the Netherlands. Spain, Portugal and the UK joined the exchange rate mechanism much later -and with a wider margin of $6 \%$ compared to $2.5 \%$ for the other membersand, hence, are not included. In addition, we do not consider countries that had pegged to the ECU, e.g. Finland and Sweden. With the exception of the first five observations of the Irish interest rate, and three observations of the French interest rate data comes from the International Financial Statistics of the IMF. The missing data were taken from the OECD's Main Economic Indicators. The data are monthly and cover the period January 1978 to December 1993.

Table 1 reports descriptive statistics for all six countries. It can be seen that, unlike the other countries, the Netherlands index has a negative mean implying that on average the country did not face severe FX market pressures. The standard deviation of the index is also the lowest in the sample. For this reason the Netherlands is not included in our estimations. ${ }^{11}$ Ireland has the highest mean of all the countries and the most volatile MPI as shown by its standard deviation. However, from the plots in Figure 1 it can be seen that the rest of the series were also quite volatile,

\footnotetext{
${ }^{10}$ The weighting scheme applied here is slightly different than the one normally seen in the literature, which simply uses the inverse of the standard deviation of each variable in the index. Our scheme normalizes this by the sum of the inverses of all standard deviations ensuring that the weights add up to $100 \%$. The relative weights are identical in the two schemes, as are the overall properties of the resulting MPIs.

${ }^{11}$ We do however check all our results by including the Netherlands in the sample. These estimations are not reported but do not alter our conclusions.
} 
with intense pressures mounting during 1992. The distributions are not normal they are leptokurtic and positively skewed. Jarque-Bera tests reject normality in all cases. All series are stationary around zero.

[Insert Figure 1 about here]

\section{Estimation Results}

\subsection{Homoscedastic MSVARs}

In the analysis that follows, the variance and, hence, the correlations between the MPIs of the five countries in the dataset are allowed to vary across regimes. This permits us to test whether the crisis state is associated with increased correlations. If true, implies the presence of common shocks or interdependence. If, in addition, the unconditional correlations significantly increase in the crisis state this could be taken as indication of contagion, assuming that we are correct in our presumption about the source country.

We begin our analysis with the simplest task of identifying common regime shifts, i.e. checking whether the indexes respond to common international shocks. This can be implemented by an MS-VAR with regime shifts in the mean of the MPI. At this stage we assume homoscedastic errors and $u_{t} \sim N I D(0, \Sigma)$. This simple setting will not produce transition probabilities consistent with the stylized facts, as the crisis periods are short compared to non-crisis periods. Hence, the restrictive assumption of heteroscedasticity is relaxed in what follows and the simple, homoscedastic case is just presented for comparison purposes. The multivariate setting can be formally expressed as:

$$
\omega_{t}=\mu\left(r_{t}\right)+\sum_{j=1}^{p} A_{j}\left(\omega_{t-j}-\mu\left(r_{t-j}\right)\right)+u_{t},
$$

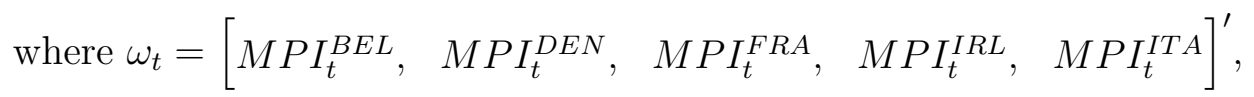

$\mu$ is a regime-dependent mean, the regime vector $r_{t}=\left[\begin{array}{llll}r_{t}, & r_{t-1}, & \ldots, & r_{t-p}\end{array}\right]^{\prime}$, matrices $A$ contain estimates of the coefficients of the $p^{t h}$-order autoregression, and $u_{t}$ 
is a gaussian error term. The criteria for lag selection do not deliver a unanimous verdict. The likelihood ratio test suggests five lags, the final prediction error and the Akaike statistic (AIC) give two, and the Hannan Quin and Schwarz criteria suggest a random walk with a drift specification. Given that the AIC is the most powerful test our preferred model features two lags. ${ }^{12}$ Assuming one lag for exposition purposes, equation (1) has a representation of the form: ${ }^{13}$

$$
\omega_{t}=\mu\left(r_{t}\right)+\sum_{j=0}^{\infty} A_{1}^{j} u_{t-j} .
$$

The process can be seen as the sum of common system shocks $\left(\mu\left(r_{t}\right)\right)$ and countryspecific shocks $\left(\sum_{j=0}^{\infty} A_{1}^{j} u_{t-j}\right)$.

The first panel of Table 2 reports the mean of regime $1\left(\mu_{1}\right)$ and the mean of regime $2\left(\mu_{2}\right)$ as well as the shift in the mean across the two regimes. Regime 1 is the tranquil state, where there are either negative pressures on the MPI (implying appreciating domestic currency or a decrease in the interest rate differential or accumulation of reserves or a combination of these) or no pressures at all, in which case the mean is close to zero. A switch to a crisis state is associated with positive means indicating mounting FX pressures. The difference between the means is in all cases positive, with Ireland's shift being the most dramatic.

\section{[Insert Table 2 about here]}

The transition probabilities estimated using two lags indicate that both regimes are quite stable. The probability of switching from a tranquil to a crisis state is $19.9 \%$, whereas the probability of a switch from crisis to tranquility is $24.3 \%$. The non-varying contemporaneous correlations (as we have assumed homoscedastic error variances do not change across states of the world) are quite high. The highest correlation is between France and Italy $(43.2 \%)$ and the lowest between France and

\footnotetext{
${ }^{12}$ We also estimate our models with $0,1,3,4,5$ and 6 lags to calibrate the impact of the lag selection on our results. No substantial changes in the results, reported later, were observed.

${ }^{13}$ See Krolzig (1997).
} 
Denmark (12.1\%). ${ }^{14}$

The assumption implicitly made in the analysis is that the mean jumps instantly to its new level across regimes. We can relax this assumption, to allow for a smoother transition to the new level. The specification now becomes

$$
\omega_{t}=\nu\left(r_{t}\right)+\sum_{j=1}^{p} A_{j}\left(\omega_{t-j}\right)+u_{t},
$$

with a representation, again with one lag, of the form

$$
\omega_{t}=\sum_{j=0}^{\infty} A_{1}^{j} \nu\left(r_{t-j}\right)+\sum_{j=0}^{\infty} A_{1}^{j} u_{t-j} .
$$

It can be seen that shocks here feed into $\omega_{t}$ through the matrix of estimated coefficients. Results are reported in the second panel of Table 2. In comparison to the model with a one-off shift in the mean, the magnitudes seem to have changed in several cases, mostly upwards. A characteristic of this model is that the crisis regime has now become much less persistent. The probability of switching to a tranquil state when in a crisis has now increased to $52.3 \%$. The correlations have also changed in some cases but always remain positive. The particularly high correlation between France and Italy remains.

\subsection{Heteroscedastic MSVARS}

We have seen that the countries in our sample face simultaneous positive FX pressures when the regime switches from tranquil to crisis. This is hardly surprising given the amount of intra-trade between the EMS countries. What is more interesting is to see whether these switches also affect the contemporaneous correlations of the cross-country MPIs. To perform this estimation we need to relax the assumption of homoscedasticity. This is a more realistic setting and is further justified since a

\footnotetext{
${ }^{14}$ Correlations between the rest of the countries are reported in Table 4, where we compare the sensitivity of correlations under different model assumptions, including the homoscedastic case.
} 
likelihood ratio test rejects the restrictions imposed by the homoscedastic model. As the variances and covariances vary across regimes we calculate two sets of correlations: one for the tranquil state and one for the crisis state. These correlations are, however, conditional on the increased volatility associated with crisis incidents and should not be used directly to make inferences on contagion.

The $\operatorname{MSIH}(2)-\operatorname{VAR}(2)$ specification delivers a $p_{11}$ (i.e. remaining in a non-crisis regime) transition probability of $87.1 \%$ whereas the $p_{22}$ (i.e. remaining in a crisis regime) transition probability is $52.6 \%$. The respective values for the $\mathrm{MSMH}(2)$ $\operatorname{VAR}(2)$ are $86.2 \%$ and $52 \%$. Both specifications deliver a similar duration for regime 1 (7.8 and 7.3 months respectively). Table 3 reports the changes in means caused by regime shifts in this heteroscedastic setting. Regime 2 is associated with higher volatility as measured by the standard errors reported.

\section{[Insert Table 3 about here]}

Table 4 reports contemporaneous correlations for both regimes and models. It also shows correlations for a simple non-switching VAR, and the homoscedastic mean-switching and intercept-switching VARs. Focusing for a moment on these last three, it can be seen that some correlations seem to be fairly robust to different specifications. For example, the coefficient for Italy and France is around $45 \%$ in all three models. Other correlations also appear quite stable, e.g. Belgium and Denmark, and Ireland and Belgium even though the magnitude of the correlation coefficient is not as high as for Italy and France. For some countries, though, the size of the correlations depends on the specification. In general, it tends to be lower in the MSI model. For example, for the simple VAR the coefficient for Italy and Belgium is $21 \%$, whereas for the MSI it is just $8 \%$. The first three panels of the table report results for homoscedastic specifications, in other words the variance is assumed not to change across regimes. We place more confidence in estimates of the correlation coefficients derived from heteroscedastic specifications, reported in the last two panels of Table 4.

[Insert Table 4 about here] 
In seven out of ten cases there is an increase in the size of the correlation coefficient during regime 2. This result holds irrespective of whether we estimate a mean-switching or an intercept-switching model. The magnitudes are also very similar. The most dramatic increases are observed between Belgium and Denmark (approximately 180\%) and France and Italy (approximately 160\%). In some cases, e.g. between France and Denmark, the correlations disappear in regime 2 or even become negative. Overall, there is evidence of increased correlation in FX pressures in the EMS during crisis periods. Using fewer lags or an extra one does not alter this finding. Increasing the memory of the VAR beyond three lags, though, produces slightly different correlations.

Figure 2 shows the 'smoothed' probabilities of a switch to the crisis regime 2 for the duration of the EMS. Our chosen specification captures well the phases of the ERM: the volatile first stage (sometimes called the 'old' EMS) when there were 12 realignments, the 'new' or 'hard' EMS between 1987 and 1992 when only 4 realignments took place and the final stage of speculative attacks during 1993 that induced Britain and Italy to abandon the mechanism and eventually led to its demise. Comparing the crisis dating depicted in the figure with the actual incidence of realignments provides us with encouraging results: 12 out of the 18 realignments plus the shock of the widening of the exchange rate bands in August 1993 are classified as crisis regimes. The regime classification (and the associated probabilities) along with the actual realignments are presented in 5 .

[Insert Figure 2 about here]

[Insert Table 5 about here]

\section{Testing for Contagion}

The timing or geographical proximity of crisis incidents do not necessarily indicate the presence of contagion effects. For example, the reason behind simultaneous 
currency pressures during a crisis state could be a common shock that induces a deterioration in the fundamental macroeconomic indicators in the affected economies. If the shock is unobservable it would be easy to mistake the effects of the disturbance for contagion. ${ }^{15}$ Therefore, one has to disentangle the role of common factors (international shocks or monsoonal effects) from the international transmission of country-specific shocks. The latter can be further classified as the effect of spillovers, if the transmission is through well-established fundamental links, or as contagion, if the transmission is 'over and above' what would be explained by such links, normally as a result of investor confidence/psychology taking over.

Under this line of thinking, if a shock in country A (which is not common to country B) induces an increase in volatility in country B (controlling for the two countries' fundamental links), the crisis can be classified as displaying contagion effects. But there are two further complications here: first, the source of the shock (the 'origin' country) needs to be known in advance; second, we need to adjust the correlations for the fact that they are a positive function of volatility.

Regarding the first issue, we examine the role of Denmark and Italy as the origin countries. As Eichengreen (2000) suggests, the rejection of the Maastricht Treaty by the Danish voters in June 2, 1991 and the competitiveness problems that Italy had accumulated over the years may have led to the demise of the ERM. The tests that follow provide substantial evidence that Denmark exported its volatility to other EMS countries. The evidence for Italy is less conclusive.

Regarding the second issue, if the cross-market correlation was high before-crisis then any shock to country A could have implications for country B. This would be described as interdependence but not as contagion (see Forbes and Rigobon, 2002). Hence, we need to correct for the effects of heteroscedasticity. If this point is not addressed, then the increased volatility in one market -a characteristic of a crisis state- could lead to increased correlations with another market even though the

\footnotetext{
${ }^{15}$ These are known in the literature as monsoonal effects, even though the term is mainly associated with the effects of major economic shifts in industrial countries on emerging economies -see Masson (1998).
} 
underlying transmission mechanism of shocks has not changed.

The 'unconditional' (corrected) correlations, as suggested by FR are given by:

$$
\rho_{U}=\frac{\rho_{C}}{\sqrt{1+\frac{\sigma_{c}-\sigma_{n c}}{\sigma_{n c}}\left(1-\rho_{C}^{2}\right)}},
$$

where $\rho_{U}$ is the unconditional correlation, $\rho_{C}$ is the conditional correlation and $\sigma$ is the standard deviation of the shock-originating country's MPI ( $c$ denotes the crisis regime and $n c$ the non-crisis regime). Dungey et al. $(2004)^{16}$ show that this test can be extended into a multivariate regression framework by estimating a system of equations, where for country A (the first equation of the system) we would have

$$
\left(\frac{\omega_{A, t}}{\sigma_{n c, A}}\right)=\phi_{A}^{\prime} \boldsymbol{\Lambda}+\chi_{A}^{\prime}\left(\boldsymbol{\Lambda} \otimes \delta_{t}\right)+\nu_{A t},
$$

where $\omega$ stands for the market pressure index, $A$ is the destination country, $t$ denotes time, $\sigma_{n c}$ is the standard deviation of the non-crisis observations, $\phi$ and $\chi$ are $(N-$ 1) $\times 1$ vectors of coefficients, matrix $\boldsymbol{\Lambda}$ contains stacked MPI observations (explained below) scaled by the non-crisis standard deviations $\boldsymbol{\Lambda}=\left[\left(\frac{\omega_{1, t}}{\sigma_{n c, 1}}\right) \ldots\left(\frac{\omega_{N-1, t}}{\sigma_{n c, N-1}}\right)\right], \delta_{t}$ is a dummy variable whose value is 1 for the crisis observations and 0 for the non-crisis observations and $\nu_{t}$ is an error term. The coefficient estimates contained in $\chi_{A}$ can be thought of as the effects of the corresponding regressors in the crisis state on country A's pressure index. If there is no change in these effects when the system is in a crisis state these coefficients should be zero and contagion is not present.

The first equation in our system is for Belgium, and, including an intercept and a dummy, can be written as

\footnotetext{
${ }^{16}$ Dungey et al. (2004) provide a useful summary of contagion tests. Other recent tests include Corsetti et al. (2005).
} 


$$
\begin{array}{r}
\left(\frac{\omega_{B E L, t}}{\sigma_{n c, B E L}}\right)=\phi_{B E L}^{0}+\phi_{B E L}^{1} \delta_{t}+\phi_{B E L, D E N}\left(\frac{\omega_{D E N, t}}{\sigma_{n c, D E N}}\right) \\
+\phi_{B E L, F R A}\left(\frac{\omega_{F R A, t}}{\sigma_{n c, F R A}}\right)+\phi_{B E L, I R L}\left(\frac{\omega_{I R L, t}}{\sigma_{n c, I R L}}\right)+\phi_{B E L, I T A}\left(\frac{\omega_{I T A, t}}{\sigma_{n c, I T A}}\right) \\
+\chi_{B E L, D E N}\left(\frac{\omega_{D E N, t}}{\sigma_{n c, D E N}}\right) \delta_{t}+\chi_{B E L, F R A}\left(\frac{\omega_{F R A, t}}{\sigma_{n c, F R A}}\right) \delta_{t}+\chi_{B E L, I R L}\left(\frac{\omega_{I R L, t}}{\sigma_{n c, I R L}}\right) \delta_{t} \\
+\chi_{B E L, I T A}\left(\frac{\omega_{I T A, t}}{\sigma_{n c, I T A}}\right) \delta_{t}+\nu_{B E L, t} ;
\end{array}
$$

the second equation, for Denmark, is

$$
\begin{array}{r}
\left(\frac{\omega_{D E N, t}}{\sigma_{n c, D E N}}\right)=\phi_{D E N}^{0}+\phi_{D E N}^{1} \delta_{t}+\phi_{D E N, B E L}\left(\frac{\omega_{B E L, t}}{\sigma_{n c, B E L}}\right) \\
+\phi_{D E N, F R A}\left(\frac{\omega_{F R A, t}}{\sigma_{n c, F R A}}\right)+\phi_{D E N, I R L}\left(\frac{\omega_{I R L, t}}{\sigma_{n c, I R L}}\right)+\phi_{D E N, I T A}\left(\frac{\omega_{I T A, t}}{\sigma_{n c, I T A}}\right) \\
+\chi_{D E N, B E L}\left(\frac{\omega_{B E L, t}}{\sigma_{n c, B E L}}\right) \delta_{t}+\chi_{D E N, F R A}\left(\frac{\omega_{F R A, t}}{\sigma_{n c, F R A}}\right) \delta_{t}+\chi_{D E N, I R L}\left(\frac{\omega_{I R L, t}}{\sigma_{n c, I R L}}\right) \delta_{t} \\
+\chi_{D E N, I T A}\left(\frac{\omega_{I T A, t}}{\sigma_{n c, I T A}}\right) \delta_{t}+\nu_{D E N, t},
\end{array}
$$

etc.

The vector of observations $\omega$ contains the non-crisis observations endogenously selected by the MS-VAR stacked upon the crisis observations. As mentioned before, both sets of non-crisis and crisis observations are scaled by the standard deviation of the non-crisis observations. As shown in Dungey et al. (2004) the multivariate version of the FR test in this regression framework is better placed to detect contagion. In addition, whereas the standard errors of (5) are based on a small sample asymptotic adjustment, the standard errors of (6) are least squares errors.

We estimate the system of five equations as seemingly unrelated regressions (SUR), a method that controls for heteroscedasticity and contemporaneous correlation. The results, reported in Table 6 , are consistent with the change in correlations across states in Table 4. As mentioned before, we focus our attention on Denmark, 
whose rejection of the Maastricht Treaty has often been blamed for triggering pessimistic market expectations that eventually led to the end of the ERM. Italy's competitiveness problems have also been blamed for the instability in the EMS. Hence, we concentrate on the $\chi$ coefficients, which we interpret as contagion effects.

[Insert Table 6 about here]

The application of the FRM test shows that Denmark was indeed affecting other countries' FX markets, as verified by the significant estimated coefficient of 0.981 . Specifically, pressures in Denmark's FX market appears to trigger pressures in Belgium and Ireland. It is noteworthy that the opposite is not true, i.e. pressures in Belgium or Ireland do not have a significant effect on Denmark's MPI movements.

The correlation with France under a crisis regime is negative. Both countries appear to be influencing each other, but Denmark's effect is greater in magnitude. Denmark's MPI does not seem to affect Italy's pressure index. It is, however, affected by it, moving in the opposite direction during a crisis state. Italy also affects France -and is affected to a lesser extent by it. Wald tests of parameter significance confirm the above conclusions.

The analysis presented here has implications for portfolio diversification. Riskaverse investors would like to hold assets whose returns are negatively correlated in a crisis state. Assuming that MPIs move largely because of movements in currencies, this property is exhibited between the Italian lira and the Danish krone (for a shock originating in Italy) and the Danish krone and the French franc (for shocks originating in any of the two countries). As an example, an investor who diversified between krone and francs would have limited losses in a crisis state. If, on the other hand, he/she had holdings in krone and Belgian francs there would have been no benefit from diversification, as in a crisis state the two currencies were be almost perfectly positively correlated.

We have then found some evidence of contagion in the exchange rate mechanism of the EMS, which seems to confirm Eichengreen's (2000) intuition about the role of Denmark's rejection of the Maastricht Treaty. The evidence for Italy is slightly 
weaker. A caveat, however, needs to be issued here that the standard errors reported may have been somewhat affected by the use of the same dataset in what is a twostep procedure. It should also be noted that the FRM test, while substantially better than others in the literature, still suffers from poor small sample properties. Dungey et al. (2005) show that the test tends to over-reject the hypothesis of no contagion.

\section{Concluding Remarks}

This paper has used a Markov switching model with fixed transition probabilities to study FX market pressures and contagion in the ERM. Using a market pressure indicator for five participant countries and allowing for regime switching and heteroscedastic errors, we find that most FX market correlations increase during the crisis state.

The features of the model are attractive for this kind of analysis. The use of a continuous crisis variable means that we do not need to choose an arbitrary cut-off point in order to define a crisis. The Markov model allows for a tranquil and a crisis state and assigns probabilities that the system was in one or the other at a given month. The chosen specification does well in defining the ERM's realignments as crisis states.

We use this endogenous determination of crisis states to implement the Dungey et al. (2004) multivariate version of the Forbes and Rigobon (2002) test to detect contagion in the EMS. We consider Denmark and Italy as the source countries (Denmark for rejecting the Maastricht Treaty and Italy because of accumulated competitiveness problems) and find that the former indeed exported its volatility Ireland and Belgium. Contagion effects appear to exist between Italy and Denmark as well. Our findings have potentially important lessons for the design of efficient portfolios aimed at reducing the risks associated with currency volatility. 


\section{Acknowledgements}

We thank participants of a seminar held at the University of Santa Clara, California and a workshop ("Portfolio Diversification and Contagion") held at Cass Business School, London. We gratefully acknowledge useful comments from Mardi Dungey, Helen Popper and a referee. Finally, we thank Panza de Paula for research assistance. Of course, all errors are ours. 


\section{References}

[1] Abiad, A., 2003. Early-Warning Systems: A Survey and a Regime-Switching Approach. IMF Working Paper no. 03/32. Washington, DC.

[2] Amato A., Tronzano M., 2000. Fiscal Policy, Debt Management and Exchange Rate Cedibility: Lessons from the Recent Italian Experience. Journal of Banking and Finance 24 (6), 921-943.

[3] Baur, D., Fry, R., 2006. Endogenous Contagion -A Panel Data Analysis. CAMA Working Paper 09. Australian National University, Centre for Applied Macroeconomic Analysis.

[4] Billio, M., Lo Duca, M., Pelizzon, L., 2005. Contagion Detection with Switching Regime Models: A Short and Long Run Analysis. GRETA Discussion Paper no. 05.01.

[5] Billio, M., Pelizzon. L., 2003. Contagion and Interdependence in Stock Markets: Have they Been Misdiagnosed? Journal of Economterics and Business 55 (5-6), 405-426.

[6] Bordo, M., Eichengreen, B., Klingebiel, D., Martinez-Peria, M. S., 2001. Is the Crisis Problem Growing More Severe? Economic Policy 16 (32), 51-82.

[7] Cerra, V., Saxena, C., 2002. Contagion, Monsoons, and Domestic Turmoil in Indonesia's Currency Crisis. Review of International Economics 10 (1), 36-44.

[8] Corsetti, G., Pericoli, M., Sbracia, M., 2005. Some Contagion, Some Interdependence: More Pitfalls in Tests of Financial Contagion. Journal of International Money and Finance 24 (8), 1177-1199.

[9] Corsetti, G., Pesenti, P., Roubini, N., 1999. Paper Tigers? A Model of the Asian Crisis. American Economic Review 43 (7), 1211-1236. 
[10] Dungey, M., Fry, R., Gonzalez-Hermosillo, B., Martin, V. L., 2004. Empirical Modelling of Contagion: A Review of Methodologies. IMF Working Paper no. 04/78. Washington DC.

[11] Dungey, M., Fry, R., Gonzalez-Hermosillo, B., Martin, V. L., 2005. A Monte Carlo Analysis of Alternative Tests of Contagion. Unpublished Working Paper, University of Melbourne.

[12] Eichengreen, B., 2000. The EMS Crisis in Retrospect. NBER Working Paper no. 8035. Cambridge, MA.

[13] Eichengreen, B., Rose, A., Wyplosz, C., 1996. Contagious Currency Crises: First Tests. Scandinavian Journal of Economics 98 (4), 463-484.

[14] Favero, C. A., Giavazzi, F., 2002. Is the International Propagation of Financial Shocks Non-Linear?: Evidence from the ERM. Journal of International Economics 57 (1), 231-246.

[15] Fazio, G., 2007. Extreme Interdependence and Extreme Contagion between Emerging Markets. Journal of International Money and Finance 26 (8), 12611291.

[16] Filardo, A. J., 1994. Business-Cycle Phases and their Traditional Dynamics. Journal of Business and Economics Statistics 12 (3), 299-308.

[17] Forbes, K. J., Rigobon, R., 2002. No Contagion, Only Interdependence: Measuring Stock Market Comovements. Journal of Finance 57 (5), 2223-2261.

[18] Glick, R., Rose, A. K., 1999. Contagion and Trade: Why are Currency Crises Regional? Journal of International Money and Finance 18 (4), 603-617.

[19] Gravelle, T., Kichian, M., Morley, J., 2006. Detecting Shift-Contagion in Currency and Bond Markets. Journal of International Economics 68 (2), 409-423.

[20] Hamilton, J., 1989. A New Approach to the Economic Analysis of Nonstationary Time Series and the Business Cycle. Econometrica 57 (2), 357-384. 
[21] Hamilton, J. D., 1994. Time Series Analysis. Princeton University Press.

[22] King, M., Sentana, E., Wadhani, S., 1994. Volatility and Links between National Stock Markets. Econometrica 62 (4), 901-933.

[23] Krolzig, H.M., 1997. Markov-Switching Vector Autoregressions. Modelling, Statistical Inference and Application to Business Cycle Analysis. Springer, Berlin.

[24] Krolzig, H.-M., 2001. Markov-Switching Procedures for Dating the Eurozone Business Cycle. Vierteljahrshefte zur Wirthschaftsforschung 70 (3), 339-351.

[25] Krugman, P., 1979. A Model of Balance of Payments Crises. Journal of Money, Credit and Banking 11 (3), 311-325.

[26] Martinez Peria, M. S., 2002. A Regime-Switching Approachto the Study of Speculative Attacks: A Focus on EMS Crises. Empirical Economics 27 (2), $299-334$.

[27] Masson, P., 1998. Contagion-Monsoonal Effects, Spillovers, and Jumps Between Multiple Equilibria. IMF Working Paper no 98/142. Washington, DC.

[28] Obstfeld, M., 1986. Rational and Self-Fulfilling Balance of Payments Crises. American Economic Review 76 (1), 72-81.

[29] Psaradakis, Z., Spagnolo, N., 2003. On the Determination of the Number of Regimes in Markov-Switching Autoregressive Models. Journal of Time Series Analysis 24 (2), 237-252.

[30] Rose, A. K., 2007. A Stable International Monetary System Emerges: Inflation Targeting is Bretton Woods, Reversed. Journal of International Money and Finance 26 (5), 663-681. 

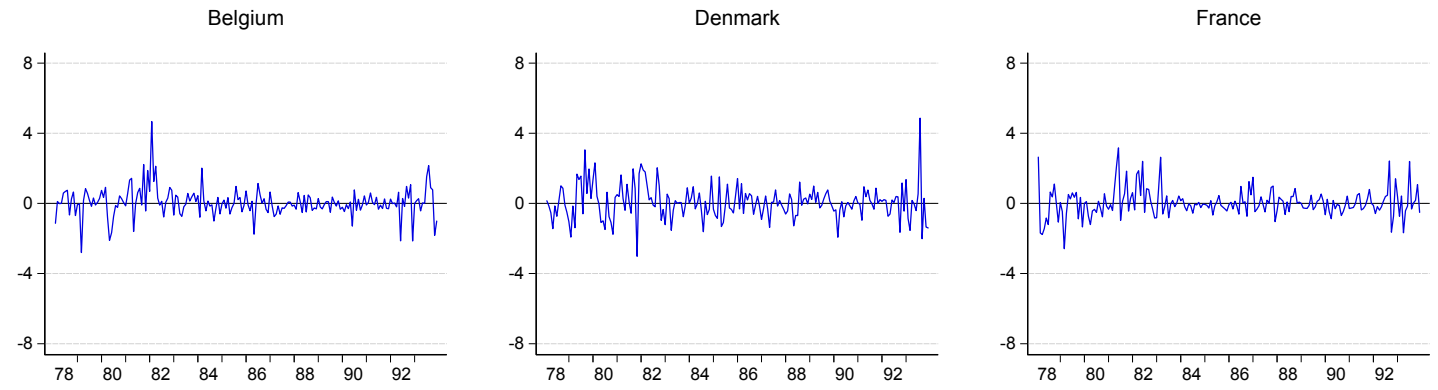

Ireland

Italy

Netherlands
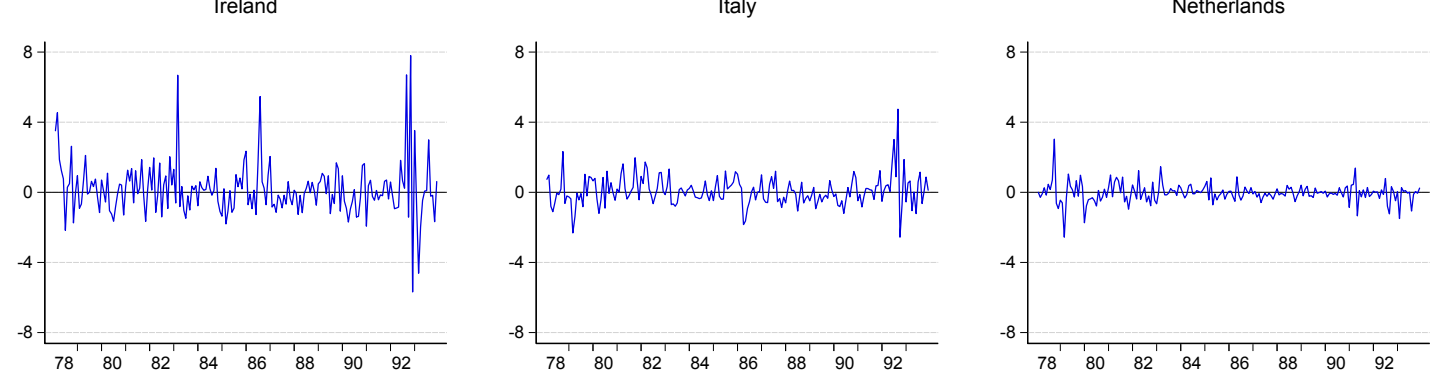

Figure 1: Market Pressure Indexes, 1979-1993 


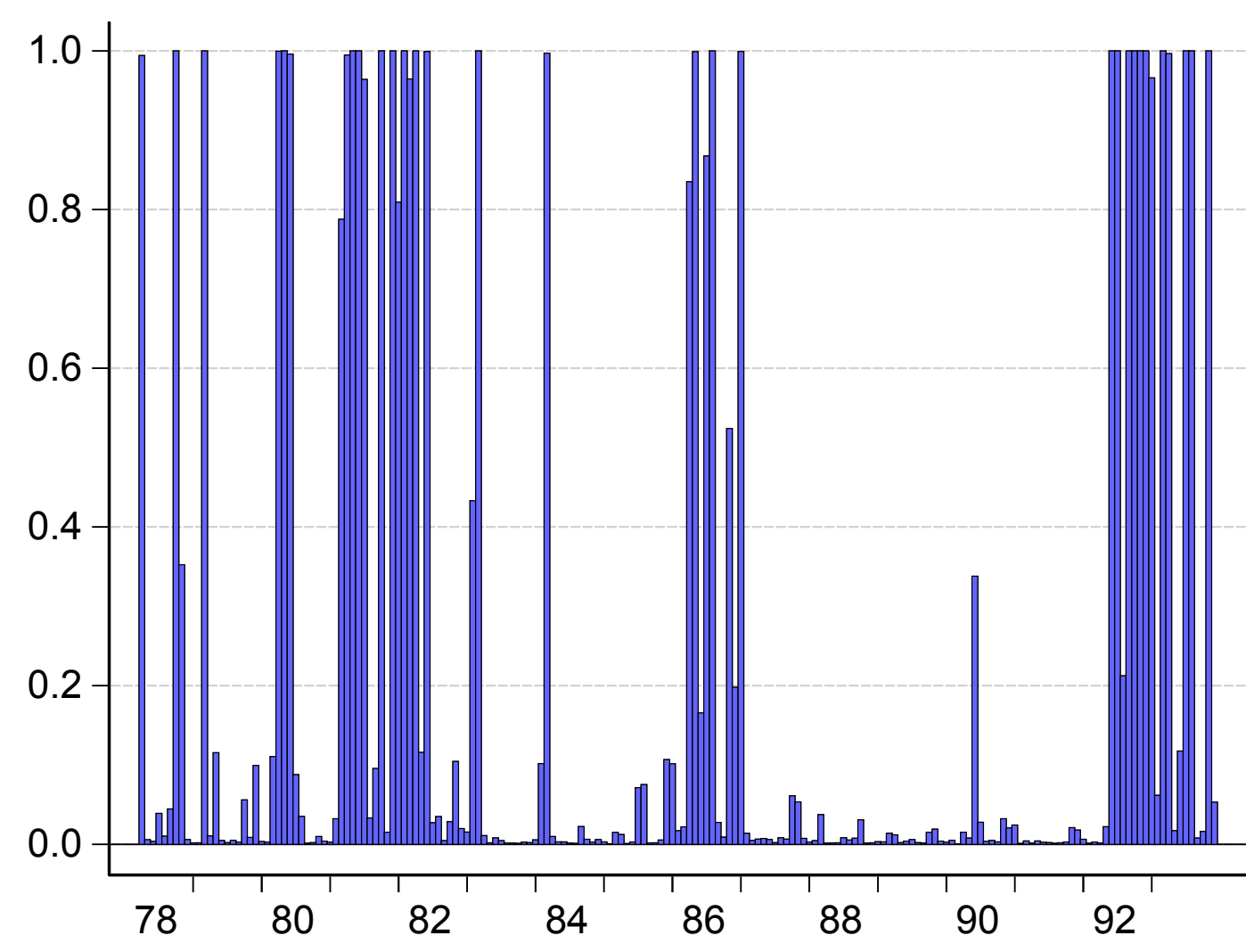

Figure 2: Smoothed Probabilities of the Crisis Regime 
Table 1: Descriptive Statistics

\begin{tabular}{lcccccr} 
& BEL & DEN & FRA & IRL & ITA & NLD \\
\hline Mean & 0.052 & 0.058 & 0.026 & 0.154 & 0.067 & -0.040 \\
Maximum & 4.669 & 4.860 & 3.167 & 7.798 & 4.735 & 3.028 \\
Minimum & -2.085 & -3.015 & -2.582 & -5.689 & -2.562 & -2.564 \\
St. Deviation & 0.797 & 0.971 & 0.801 & 1.549 & 0.843 & 0.546 \\
Skewness & 0.742 & 0.681 & 0.907 & 1.405 & 1.044 & 0.392 \\
Kurtosis & 7.070 & 3.179 & 3.003 & 7.010 & 5.319 & 7.481 \\
No. of Obs. & 191 & 191 & 191 & 191 & 191 & 191 \\
\hline \hline
\end{tabular}


Table 2: Homoscedastic $\operatorname{MSM}(2)-\operatorname{VAR}(2)$ and $\operatorname{MSI}(2)-\operatorname{VAR}(2)$

\begin{tabular}{lccccr} 
& BEL & DEN & FRA & IRL & ITA \\
\hline$\mu_{1}$ & -0.072 & -0.321 & -0.2 & -0.365 & -0.168 \\
$\mu_{2}$ & 0.206 & 0.524 & 0.293 & 0.686 & 0.335 \\
$\mu_{2}-\mu_{1}$ & 0.278 & 0.845 & 0.493 & 1.051 & 0.503 \\
\hline$\nu_{1}$ & -0.053 & -0.157 & -0.036 & -0.249 & -0.115 \\
$\nu_{2}$ & 0.474 & 1.199 & 0.273 & 1.876 & 0.882 \\
$\nu_{2}-\nu_{1}$ & 0.527 & 1.356 & 0.309 & 2.125 & 0.997 \\
\hline \hline
\end{tabular}

Notes: Non-linear Markov-switching estimations with regime-dependent means (panel 1) or intercepts (panel 2) and homoscedastic errors. Order of VAR: 2. Number of regimes: 2. MSM: switching mean - see equation 1 in text. MSI: switching intercept - see equation 3. Results were obtained using H-M. Krolzig's MSVAR package for Ox. 
Table 3: Heteroscedastic $\operatorname{MSM}(2)-\operatorname{VAR}(2)$ and $\operatorname{MSI}(2)-\operatorname{VAR}(2)$

\begin{tabular}{lccccr} 
& BEL & DEN & FRA & IRL & ITA \\
\hline$\mu_{1}$ & -0.010 & -0.042 & -0.093 & -0.081 & -0.021 \\
$\mu_{2}$ & 0.31 & 0.399 & 0.491 & 0.576 & 0.399 \\
$\mu_{2}-\mu_{1}$ & 0.32 & 0.441 & 0.584 & 0.657 & 0.42 \\
\hline$S E_{1}$ & 0.397 & 0.867 & 0.445 & 0.835 & 0.521 \\
$S E_{2}$ & 1.45 & 1.046 & 1.27 & 2.579 & 1.413 \\
\hline \hline$\nu_{1}$ & -0.012 & -0.024 & -0.083 & -0.092 & -0.029 \\
$\nu_{2}$ & 0.239 & 0.355 & 0.431 & 0.741 & 0.339 \\
$\nu_{2}-\nu_{1}$ & 0.251 & 0.379 & 0.514 & 0.833 & 0.368 \\
\hline$S E_{1}$ & 0.399 & 0.875 & 0.45 & 0.86 & 0.524 \\
$S E_{2}$ & 1.486 & 1.056 & 1.306 & 2.607 & 1.44 \\
\hline \hline
\end{tabular}

Notes: Non-linear Markov-switching estimations with regime-dependent means (panel 1) or intercepts (panel 2) and heteroscedastic errors. SE: standard error. Order of VAR: 2. Results were obtained using H-M. Krolzig's MSVAR package for Ox. 
Table 4: Correlations

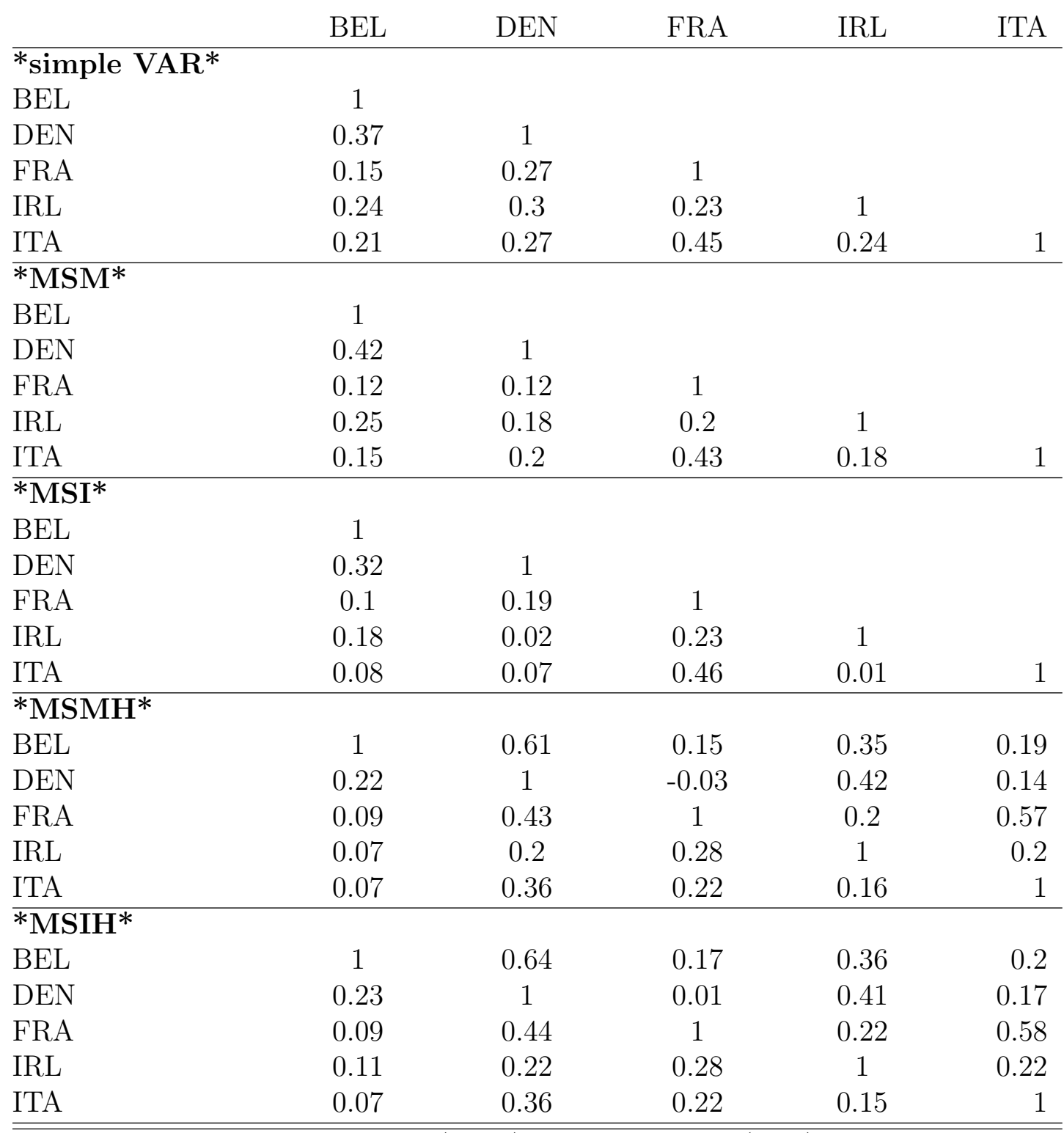

Notes: For the heteroscedastic mean-switching (MSMH) and intercept-switching (MSIH) specifications, numbers below the main diagonal are regime 1 correlations whereas numbers above the main diagonal are regime 2 correlations. Order of all VARs: 2. Results were obtained using H-M. Krolzig's MSVAR package for Ox. 
Table 5: Regime Classification and Actual Realignments

\begin{tabular}{lllr} 
Tranquil Regime 1 & Realignment & Crisis Regime 2 & Realignment \\
\hline 1978:5 - 1978:9 $(0.9794)$ & & $1978: 4-1978: 4(0.9940)$ & \\
1978:11 - 1979:2(0.9096) & & $1978: 10-1978: 10(0.9998)$ & \\
$1979: 4-1980: 3(0.9649)$ & {$[2]$} & $1979: 3-1979: 3(1.0000)$ & {$[1]$} \\
1980:7 $-1981: 2(0.9782)$ & & $1980: 4-1980: 6(0.9985)$ & {$[1]$} \\
$1981: 8-1981: 9(0.9358)$ & & $1981: 3-1981: 7(0.9492)$ & {$[1]$} \\
$1981: 11-1981: 11(0.9848)$ & & $1981: 10-1981: 10(1.0000)$ & {$[1]$} \\
$1982: 5-1982: 5(0.8843)$ & & $1981: 12-1982: 4(0.9548)$ & {$[1]$} \\
$1982: 7-1983: 2(0.9166)$ & & $1982: 6-1982: 6(0.9990)$ & {$[1]$} \\
$1983: 4-1984: 2(0.9872)$ & {$[1]$} & $1983: 3-1983: 3(1.0000)$ & {$[1]$} \\
$1984: 4-1986: 3(0.9795)$ & {$[1]$} & $1984: 3-1984: 3(0.9970)$ & {$[3]$} \\
$1986: 6-1986: 6(0.8345)$ & & $1986: 4-1986: 5(0.9170)$ & {$[1]$} \\
$1986: 9-1986: 10(0.9817)$ & & $1986: 7-1986: 8(0.9337)$ & \\
$1986: 12-1986: 12(0.8023)$ & & $1986: 11-1986: 11(0.5240)$ & \\
$1987: 2-1992: 5(0.9852)$ & {$[1]$} & $1987: 1-1987: 1(0.9990)$ & \\
$1992: 8-1992: 8(0.7877)$ & & $1992: 6-1992: 7(1.0000)$ & \\
$1993: 2-1993: 2(0.9383)$ & {$[1]$} & $1992: 9-1993: 1(0.9932)$ & \\
$1993: 5-1993: 6(0.9327)$ & {$[1]$} & $1993: 3-1993: 4(0.9982)$ & \\
$1993: 9-1993: 10(0.9880)$ & & $1993: 7-1993: 8(1.0000)$ & \\
$1993: 12-1993: 12(0.9469)$ & & $1993: 11-1993: 11(1.0000)$ & \\
\hline \hline
\end{tabular}

Notes: Regime probabilities are from a MSIH(2)-VAR(2) model. The numbers in brackets indicate the number of actual realignments. 
Table 6: FRM Regression Results

\begin{tabular}{lccccr} 
& BEL & DEN & FRA & IRL & ITA \\
\hline Constant & 0.022 & 0.053 & -0.15 & -0.031 & 0.037 \\
$\delta$ & $(0.126)$ & $(0.075)$ & $(0.108)$ & $(0.123)$ & $(0.103)$ \\
& -0.347 & 0.054 & $0.519^{* *}$ & 0.369 & -0.188 \\
$\phi_{B E L}$ & $(0.305)$ & $(0.179)$ & $(0.261)$ & $(0.296)$ & $(0.25)$ \\
& - & $0.27^{*}$ & 0.004 & 0.124 & 0.043 \\
$\phi_{D E N}$ & - & $(0.072)$ & $(0.111)$ & $(0.123)$ & $(0.104)$ \\
& $0.559^{*}$ & - & $0.41^{*}$ & $0.275^{* *}$ & $0.291^{*}$ \\
$\phi_{F R A}$ & $(0.135)$ & - & $(0.115)$ & $(0.136)$ & $(0.111)$ \\
& -0.104 & $0.365^{*}$ & - & 0.167 & $0.313^{*}$ \\
$\phi_{I R L}$ & $(0.138)$ & $(0.077)$ & - & $(0.133)$ & $(0.105)$ \\
& 0.12 & $0.129^{* * *}$ & 0.172 & - & 0.057 \\
$\phi_{I T A}$ & $(0.128)$ & $(0.076)$ & $(0.111)$ & - & $(0.105)$ \\
& 0.009 & $0.267^{*}$ & $0.383^{*}$ & 0.086 & - \\
$\chi_{B E L}$ & $(0.13)$ & $(0.075)$ & $(0.106)$ & $(0.127)$ & - \\
& - & 0.014 & 0.021 & -0.084 & 0.023 \\
$\chi_{D E N}$ & - & $(0.084)$ & $(0.135)$ & $(0.15)$ & $(0.126)$ \\
& $0.981^{*}$ & - & $-0.542^{*}$ & $0.597^{* *}$ & -0.118 \\
$\chi_{F R A}$ & $(0.236)$ & - & $(0.231)$ & $(0.254)$ & $(0.219)$ \\
& 0.188 & $-0.362^{*}$ & - & -0.029 & $0.348^{*}$ \\
$\chi_{I R L}$ & $(0.173)$ & $(0.098)$ & - & $(0.167)$ & $(0.126)$ \\
& -0.074 & 0.038 & -0.074 & - & 0.013 \\
$\chi_{I T A}$ & $(0.157)$ & $(0.091)$ & $(0.136)$ & - & $(0.129)$ \\
& 0.138 & $-0.242^{* *}$ & $0.438^{* *}$ & 0.009 & - \\
\hline \hline \multirow{2}{*}{} & $(0.177)$ & $(0.103)$ & $(0.135)$ & $(0.173)$ & - \\
\hline
\end{tabular}

Notes: The table provides SUR estimates of a system of equations, where each equation has the form of (6) in the text. $(*),\left({ }^{* *}\right)$ and $\left({ }^{* *}\right)$ denote significance at the 1,5 and 10 percent level, respectively. 